\title{
Verification of Hypothesis of "Six Patterns of Paid Vacation Use": An Exploration of Six Patterns of Paid Vacation Usage and Number of Days Taken
}

\author{
Go Igusa \\ J.F. Oberlin University, Tokyo, Japan \\ Email: m-spo@y.suou.waseda.jp
}

Received 20 June 2014; revised 27 July 2014; accepted 11 August 2014

Copyright (C) 2014 by author and Scientific Research Publishing Inc. This work is licensed under the Creative Commons Attribution International License (CC BY). http://creativecommons.org/licenses/by/4.0/

(c) (i) Open Access

\begin{abstract}
In this study a survey using questionnaires was conducted to understand the actual condition of the relationship between methods for taking paid vacation and its usage rate, to focus on verifying the relationship quantitatively by empirical analysis, and to present a plan to promote paid vacation usage. The simple tabulation did not reveal a distinct difference in the number of days taken as paid vacation among the usage methods; however, by making the other conditions constant, the number of days taken as paid vacation by those adopting a share method was significantly high. In other words, by recommending the share method at a workplace, it is possible that the paid vacation usage condition improves considerably. In order for this method to operate effectively, the paper proposed that "efforts to utilize human resources" is necessary so that personnel who can replace the work of employees taking paid vacation are prepared.
\end{abstract}

\section{Keywords}

Paid Vacation, Share Method, Progressive Method, Regressive Method, Self-Pay Method

\section{Introduction}

\subsection{Awareness of Issues}

Paid vacation was not well-researched until recent years, except for research and studies done in the early 2000's by Kazuya Ogura [1] and the Institute for Free Time Design. This is because in Japan, not taking paid 
vacation was considered a serious commitment of a worker to a company, and was recognized by researchers as an "unwritten rule" in the society.

In Japan, there have been various labor issues such as an increase of part-time workers and NEET, diversification of employment patterns, rationalization derived from globalization and corporate downsizing. The paid vacation issue is not only one of serious labor issues, but it is closely related to many other labor issues. Furthermore, in recent years, commitment to a company by Japanese workers has changed: The awareness has been changing from "do not take paid vacation" to "cannot take paid vacation". It is suggested that research or a study that can contribute to the promotion of paid vacation usage is necessary.

\subsection{Study Subjects}

This paper aims to present a plan for promoting paid vacation usage. For this purpose, the "replacement problem" or "management of paid vacation", the biggest inhibiting factor for paid vacation usage, was clarified using a qualitative analysis method generated from outstanding research on paid vacations in the past, the actual relationship between methods of usage and paid vacation usage rates was confirmed and this paper considered what kind of operation management would be applicable to paid vacation in order to improve paid vacation usage rates.

\section{Preceding Studies}

Preceding studies considered to be significant are organized in chronological order in reference to the paper's interest in capturing and interpreting "administration of paid vacation” from multiple aspects. Specifically, research with paid vacation usage as a main subject and peripheral research related to paid vacation (childcare leave, etc.) were discussed and study subjects were presented.

Matsuzaki [2] presented a calculation method that takes into account non-work days as well as vacation days within manufacturing industries that require an advanced division of labor and cooperation. According to this method the number of replacement workers is defined by the number of factory operation days and vacation days, as shown in the following formula:

$$
\text { Non-work day addition rate }=\frac{\text { vacation days }}{\text { annual factory operation days }- \text { vacation days }} \times 100
$$

In this formula, if the annual factory operation days are defined as 365 days, a workplace with continuous operation will require the following non-work days to be added depending on vacation days:

$<$ When the number of annual vacation days is $68>$

$$
\text { Addition rate }=\frac{68}{365-68} \times 100 \fallingdotseq 23 \%
$$

In other words, if the number of annual vacation days is 68 , the net personnel will increase by $23 \%$. When considering paid vacation usage, the addition rate increases as the vacation days in this formula increase. If continuous operation has to stop due to lack of personnel caused by employees taking vacation, the company will lose profits; in order to avoid such a large risk, a personnel plan that takes vacation such as paid vacation into an account is prepared. However, although a calculation formula for obtaining the number of replacement workers for paid vacation is indicated, the relevant research does not include a method for how to rotate personnel.

Wakisaka [3] "Conditions and Issues for Utilizing Childcare Leave System at a Workplace" clarifies that two methods, a "share" method and a "progressive" method, are used for administering childcare operation at a workplace. The "share" method is to divide a task and add a portion for colleagues. The "progressive" method pushes employees in a chain-reaction way when one of them takes vacation. The research concludes "the former can increase productivity in the short term but the latter has more advantages in the long term”. However, paid vacation is different from childcare leave in that the vacation time is short and it is often taken in segments. Therefore, its rotation method and selection criteria are also different from that of childcare leave.

Igusa [4] linked the research results and achievements by 1) Matsuzaki [2] and 2) Wakisaka [3] and examined the difference in the characteristics of rotation patterns of paid vacation usage. The study clarified what types were found in behaviors for ensuring replacement personnel, indicated what kind of people fit into each type based on empirical generalization, and indicated why it was easier for certain workers to choose certain beha- 
vioral types.

Specifically, using opportunistic sampling, Igusa [4] conducted semi-structured interviews with 49 workers who are full-time employees or staff members. By utilizing a qualitative and descriptive research method, the study defines "six patterns of paid vacation use" (share, progressive, regressive, self-pay in advance, self-pay in arrears and self-pay by working at home) as follows:

1) Share method: The task of an employee taking paid vacation is divided into small portions to be shared by his/her colleagues. This method was observed relatively more in a workplace where many employees are engaged in the same tasks. The number of employees taking paid vacation who used this method was the highest, and the paid vacation usage rate was also high. Therefore, one may infer that it is easier to take paid vacation using this method over others.

2) Progressive method: The task of an employee taking paid vacation is performed by another employee whose task is one-rank easier. This method was mainly used by workers with advanced careers. Even if there are many employees in the entire workplace, the number of workers engaged in the same task becomes less as the career advances. Therefore in this case, the share method does not function effectively, so workers with advanced careers take paid vacation using the progressive method.

3) Regressive method: The task of an employee taking paid vacation is covered by his/her superior within the same group, team or section. This method was observed in a workplace with a small number of employees, thus a small number of workers could manage the same task. This method requires that the superior acknowledges some understanding for paid vacation usage.

4) Self-pay method (advance, arrears, work at home): The task on the paid vacation day is managed by the employee taking paid vacation rather than by another employee. The paid vacation usage rate of workers utilizing this method was relatively low. This method was more significant in cases where the amount of work is always big, and particularly when a manager or a superior does not support paid vacation.

The research then examined the relationship between the paid vacation usage rate and the usage methods using Table 1, which reorganizes the attributes of interview subjects into: Types of business $\rightarrow$ job categories $\rightarrow$ length of service. The research further pointed out the importance of various efforts for workload management, utilization of personnel and diverse creative efforts at a workplace. However, in order to discuss the relationship between the paid vacation usage rate and the usage methods, it is not sufficient to simply reorder the variables. It is important to measure results by making other conditions constant.

Upon reviewing the preceding studies regarding the "management of paid vacation" and the peripheral studies, it can be noted that, for understanding quantitatively the relationship between the paid vacation usage rate and the usage methods, there is a limit derived from research methods. This is observed in Igusa [4], which referred to 1) Matsuzaki [2] (1982) and 2) Wakisaka [3] and conducted interviews with employees at a workplace and clarified the difference in the characteristics of rotation patterns for taking paid vacation. In other words, since the research adopted only the case study method based on intensive observation through interviews, the nature and tendency of the subject group was not accurately captured. The number of samples in this research was extremely small compared to larger surveys and its representativeness was not ensured by random sampling or other sampling techniques. Enhancing random sampling, representativeness and comparability is important for conducting scientific research. Therefore, this study aims to find clues for promoting paid vacation usage by understanding the actual situation of the relationship between the paid vacation usage rates and the usage method based on questionnaires, followed by empirical analysis to confirm the results quantitatively.

\section{Outline of Questionnaires and the Summary of Count Results}

The survey was conducted by reviewing questions in reference to the research outcomes concerning the management of paid vacation (described in Chapter 2), targeting full-time employees, 20 - 59 years old, among the monitors across Japan retained by a private research company (Gain, Inc.) and using the Internet (the range of subject age was based on the latest "Survey on Paid Vacation Use"). Regarding sampling, random sampling was chosen. The period that the survey was conducted was four days, from May 1 to May 4, 2013. The number of questionnaires distributed was 535, the number of recovered questionnaires was 423 (recovery rate $79.1 \%$ ). As a result of removing invalid questionnaires and processing abnormal values of valid questionnaires, the sample size for the analysis became 201.

The details of questions and the results of simple tabulation were included in the survey sheet attached at the 
Table 1. Individual and workplace attributes of interview subjects and rotation types.

\begin{tabular}{|c|c|c|c|c|c|c|c|c|}
\hline Name & $\begin{array}{c}\text { Type of } \\
\text { Business }\end{array}$ & Job Category & $\begin{array}{l}\text { Length of } \\
\text { Service }\end{array}$ & Company Size & Education & $\begin{array}{c}\text { Number of } \\
\text { Employees at } \\
\text { Work }\end{array}$ & $\begin{array}{l}\text { Rate of Paid } \\
\text { Vacation } \\
\text { Use }\end{array}$ & Rotation Type \\
\hline $\begin{array}{c}\text { A } \\
\text { (Male, 32) }\end{array}$ & Medicine & Surgeon & 6 years & Large & Undergraduate & Many & $15 \%$ & Share \\
\hline $\begin{array}{c}\text { B } \\
\text { (Male, 35) }\end{array}$ & Medicine & $\begin{array}{l}\text { Cosmetic } \\
\text { Surgeon }\end{array}$ & 6 years & Medium & Undergraduate & Standard & $20 \%$ & Share \\
\hline $\begin{array}{c}\mathrm{U} \\
\text { (Male, 29) }\end{array}$ & Medicine & $\begin{array}{l}\text { Orthopedic } \\
\text { Surgeon }\end{array}$ & 1 year & Large & Undergraduate & Standard & $5 \%$ & Share \\
\hline $\begin{array}{c}\mathrm{Q} \\
\text { (Male, 31) }\end{array}$ & Medicine & Dentist & 5 years & Small & Undergraduate & Few & $10 \%$ & Share \\
\hline $\begin{array}{c}\text { I } \\
\text { (Female, 34) }\end{array}$ & Medicine & Dentist & 3 years & Small & Graduate & Few & $5 \%$ & Share \\
\hline $\begin{array}{c}\mathrm{T} \\
\text { (Female, 41) }\end{array}$ & Medicine & Dentist & 2 years & Medium & Graduate & Few & $20 \%$ & Division \\
\hline $\begin{array}{c}\text { F } \\
\text { (Male, 32) }\end{array}$ & Medicine & Pharmacist & 8 years & Small & Undergraduate & Few & $30 \%$ & Division \\
\hline $\begin{array}{c}\text { M } \\
\text { (Female, 53) }\end{array}$ & Medicine & Pharmacist & 7 years & Large & Undergraduate & Few & $40 \%$ & Progressive \\
\hline $\begin{array}{c}\text { B2 } \\
\text { (Female, 23) }\end{array}$ & Medicine & Pharmacist & 1 year & Large & Undergraduate & Standard & $50 \%$ & Share \\
\hline $\begin{array}{c}P \\
\text { (Male, 44) }\end{array}$ & Air travel & Pilot & 12 years & Large & Undergraduate & Many & $95 \%$ & Share \\
\hline $\begin{array}{c}\text { D } \\
\text { (Female, 34) }\end{array}$ & Air travel & Cabin attendant & 12 years & Large & Vocational & Many & $80 \%$ & Share \\
\hline
\end{tabular}

Note 1: Interview subjects E and others are omitted. Source: Igusa [4] "Six Patterns of Paid Vacation Use: A Study Concerning the Management of Paid Vacation at a Workplace Level,” Annual Review of Japanese Association of Labor Sociology, 22:86-87; 2011.

end of this paper. Here, the results of simple tabulation regarding the relationship between the paid vacation usage and the usage methods are introduced. The rate of employees who took paid vacation and each usage method are shown in Table 2; Table 3 indicates the number of paid vacation days taken by each usage method.

The number of those who took paid vacation using the "self-pay (advance)" method was the highest (44.7\%), followed by the "share" method (28.2\%).

As for the number of paid vacation days taken by usage method, the "progressive" method was the highest (10.1 days), followed by the "self-pay (arrears)" (8.7 days). Although the difference of paid vacation days taken by usage method was verified using the analysis of variance for one-way layout, there was no significant difference $(F(5,341)=1.20, p>0.10)$.

\section{Variables/Analysis Method and Results}

Now, which method has influence on paid vacation usage? The following section verifies the usage methods by conducting a censored model regression analysis with the number of paid vacation days taken as variables. There were 25 cases in which the number of days taken as paid vacation was " 0 " ( $8 \%$ of 201 valid samples). Therefore, when choosing an analysis method, the study adopted the censored model that is appropriate for a distribution with disconnected dependent variables. 
Table 2. Rate of employees who took paid vacation using each usage method.

\begin{tabular}{ccccccc}
\hline & & \multicolumn{5}{c}{ Paid Vacation Usage Methods } \\
& Share & Progressive & Regressive & Self-Pay, Advance & Self-Pay, Arrear & Self-Pay, Work at Home \\
\hline $\begin{array}{c}\text { Mean } \\
\text { Standard }\end{array}$ & 7.4 & 10.1 & 6.0 & 7.3 & 8 & 6.2 \\
Deviation & 6.4 & 6.4 & 6.3 & 6.0 & 6.9 & 7.8 \\
\hline
\end{tabular}

Table 3. Number of paid vacation days taken by each use method.

\begin{tabular}{|c|c|c|c|c|c|c|}
\hline & \multicolumn{6}{|c|}{ Paid Vacation Usage Methods } \\
\hline & Share & Progressive & Regressive & Self-Pay, Advance & Self-Pay, Arrear & Self-Pay, Work at Home \\
\hline $\begin{array}{c}\text { Frequency } \\
\text { (Rate) }\end{array}$ & $98(28.2 \%)$ & $15(4.3 \%)$ & $23(6.6 \%)$ & $155(44.7 \%)$ & $45(13.0 \%)$ & $11(3.2 \%)$ \\
\hline
\end{tabular}

In order to study the influence of the usage methods on paid vacation income, a dummy variable was used as an independent variable for each usage method. For control variables, variables related to the basic attributes and work styles as well as actual working hours per week and the number of predetermined non-work days per week were used. The descriptive statistics of variables used for the analysis are shown in Table 4; the results are indicated in Table 5.

The following can be gleaned from this. First of all, it can be understood that the share method and the self-pay method (work at home) become significant and that there is a clear difference in the number of paid vacation days depending on method of usage.

Secondly, it can be understood that if suitable workload management is implemented to correspond to personnel, this has a real effect on the number of paid vacation days.

Thirdly, as a reference, we would like to compare samples that were collected through internet research and the results of qualitative analysis of these with the results of previous research by Ogura [1] in which samples were collected through a large-scale survey with the number of paid vacation days as dependent variables. Ogura [1] discovered that the larger the company, the higher the yearly salary and the more paid vacation days that are granted, the easier it is for workers to take paid vacations. In addition, there are differences between industries and it has been discovered that it is difficult for workers in the service industry to take paid vacation.

In response, the higher the number of paid vacation days that are granted, the more paid vacations days are taken in this model, too. In addition, the number of paid vacation days for workers in wholesale, retail, medicine/welfare of who many are in the service industry, is low. From here, it can be understood that the results of analysis of this study using internet research are consistent with the results of analysis of previous research to a certain extent.

\section{Discussion and Conclusions}

Although the simple tabulation did not reveal a distinct difference in the number of days taken as paid vacation among the usage methods, by making the other conditions constant, the number of days taken as paid vacation by those adopting a share method was significantly high. In other words, by recommending the share method at a workplace, it is possible that the paid vacation usage condition improves considerably. In order for this method to operate effectively, "efforts to utilize human resources” are necessary. It is important to prepare workers who can take the work of employees taking paid vacation, and if such efforts are achieved, a labor environment will be established that enables workers to take paid vacation more easily. Building interchangeability of work, as Hazama [5] described, is challenging unless there is a good workplace culture. Therefore, it can be said that it is necessary to nurture human resources along with a good workplace culture. Regarding interchangeability of work, Hazama [5] noted as follows: "Not only to teach procedures and skills for completing a certain task, it is important to provide experience to handle other tasks in one's workplace. That is, unless territorial conflicts over work decrease, [interchangeability of work] is impossible. Under a good workplace culture, interchangeability of work will be possible among members of a workplace.” Also, the simple tabulation shows that the number of 
Table 4. Descriptive statistics.

\begin{tabular}{|c|c|c|c|c|}
\hline Name of Variables & Average & SD & Maximum & Minimum \\
\hline Number of days taken as paid vacation & 8.15 & 6.01 & 20 & 0 \\
\hline Age & 37.63 & 8.83 & 59 & 21 \\
\hline Male* & 0.79 & 0.41 & 1 & 0 \\
\hline Middle school $^{*}$ & 0.02 & 0.14 & 1 & 0 \\
\hline High school* & 0.24 & 0.42 & 1 & 0 \\
\hline Vocational and other school ${ }^{*}$ & 0.13 & 0.33 & 1 & 0 \\
\hline Junior college/vocational high school $^{*}$ & 0.07 & 0.26 & 1 & 0 \\
\hline Undergraduate $^{*}$ & 0.45 & 0.50 & 1 & 0 \\
\hline Graduate (Master's degree program) and higher* & 0.10 & 0.30 & 1 & 0 \\
\hline Manufacturing* $^{*}$ & 0.18 & 0.38 & 1 & 0 \\
\hline Resource/energy (electric power, gas, water) ${ }^{*}$ & 0.03 & 0.16 & 1 & 0 \\
\hline Traffic/transportation (railroad, road transport, transportation by water, aviation)* & 0.05 & 0.22 & 1 & 0 \\
\hline $\begin{array}{c}\text { Education/information/publishing } \\
\text { (broadcasting, telecommunication, publishing, information processing) }\end{array}$ & 0.21 & 0.40 & 1 & 0 \\
\hline Commerce/logistics (wholesale, retail) ${ }^{*}$ & 0.10 & 0.29 & 1 & 0 \\
\hline Service/general (restaurant, tourism, hotel, etc.) ${ }^{*}$ & 0.09 & 0.28 & 1 & 0 \\
\hline Finance/insurance/real estate ${ }^{*}$ & 0.07 & 0.25 & 1 & 0 \\
\hline Construction/Materials/Forestry $^{*}$ & 0.06 & 0.23 & 1 & 0 \\
\hline Medical, welfare $^{*}$ & 0.10 & 0.30 & 1 & 0 \\
\hline Other non-manufacturing industry $^{*}$ & 0.10 & 0.29 & 1 & 0 \\
\hline Public-owned/public service (government/public enterprise/special corporation) ${ }^{*}$ & 0.05 & 0.22 & 1 & 0 \\
\hline Less than $29^{*}$ & 0.16 & 0.37 & 1 & 0 \\
\hline $30-99^{*}$ & 0.21 & 0.40 & 1 & 0 \\
\hline $100-499^{*}$ & 0.27 & 0.44 & 1 & 0 \\
\hline 500 and more ${ }^{*}$ & 0.37 & 0.48 & 1 & 0 \\
\hline Number of people per office & 323.57 & 648.88 & 3800 & 1 \\
\hline Number of people per department/section & 36.66 & 53.58 & 360 & 1 \\
\hline $\begin{array}{l}\text { Production (direct/indirect department of a factory, } \\
\text { etc. such as processing, assembly, inspection, and machine operation) }\end{array}$ & 0.07 & 0.25 & 1 & 0 \\
\hline Clerical $^{*}$ & 0.24 & 0.42 & 1 & 0 \\
\hline $\begin{array}{l}\text { Professional/technical (research and development, } \\
\text { design, information processing, teacher, designer, etc.) }\end{array}$ & 0.40 & 0.49 & 1 & 0 \\
\hline $\begin{array}{l}\text { Transportation (operation, maintenance, and loading/unloading } \\
\text { of a transportation facility and related work) }\end{array}$ & 0.04 & 0.18 & 1 & 0 \\
\hline Business management/sales* & 0.18 & 0.38 & 1 & 0 \\
\hline Other $^{*}$ & 0.09 & 0.29 & 1 & 0 \\
\hline Labor union, yes* & 0.37 & 0.48 & 1 & 0 \\
\hline Annual income (log) & 6.10 & 0.45 & 7.1 & 4.6 \\
\hline
\end{tabular}




\section{Continued}

\begin{tabular}{|c|c|c|c|c|}
\hline Actual working hours per week & 46.80 & 9.13 & 90 & 30 \\
\hline Predetermined non-work days per week & 1.93 & 0.25 & 3 & 1 \\
\hline Paid vacation days given & 15.96 & 5.12 & 28 & 5 \\
\hline Share method ${ }^{*}$ & 0.26 & 0.44 & 1 & 0 \\
\hline Progressive method* & 0.05 & 0.21 & 1 & 0 \\
\hline Regressive method ${ }^{*}$ & 0.07 & 0.26 & 1 & 0 \\
\hline Self-pay method (advance) ${ }^{*}$ & 0.46 & 0.50 & 1 & 0 \\
\hline Self-pay method (arrears) ${ }^{*}$ & 0.15 & 0.36 & 1 & 0 \\
\hline Self-pay method (work at home) ${ }^{*}$ & 0.02 & 0.14 & 1 & 0 \\
\hline Information sharing* $^{*}$ & 0.78 & 0.42 & 1 & 0 \\
\hline Sensitivity to other employees ${ }^{*}$ & 0.68 & 0.47 & 1 & 0 \\
\hline Work load management appropriate for personnel ${ }^{*}$ & 0.50 & 0.50 & 1 & 0 \\
\hline
\end{tabular}

Note 1: SD = Standard Deviation. Note 2: Sample Size $=201$. Note 3: $*=$ Dummy Variable.

Table 5. Influence of usage methods on paid vacation usage (censored model). Dependent Variable = Number of Paid Vacations used. Sample Size $=201$. Left Censored Obs $=25$. Log likelihood $=566.542$.

\begin{tabular}{|c|c|c|}
\hline Name of variables & Factor value & $\mathrm{P}$ value \\
\hline Age & 0.044 & 0.467 \\
\hline Male & -1.189 & 0.342 \\
\hline Middle school & 1.224 & 0.695 \\
\hline High school & -0.015 & 0.990 \\
\hline Vocational and other school & -0.593 & 0.680 \\
\hline Junior college/vocational high school & -2.953 & 0.086 \\
\hline \multicolumn{3}{|l|}{ (Undergraduate) } \\
\hline Graduate (Master's degree program) and higher & 0.907 & 0.569 \\
\hline \multicolumn{3}{|l|}{ (Manufacturing) } \\
\hline Resource/energy (electric power, gas, water) & -1.772 & 0.521 \\
\hline Traffic/transportation (railroad, road transport, transportation by water, aviation) & -4.458 & 0.228 \\
\hline Education/information/publishing (broadcasting, telecommunication, publishing, information processing) & -2.805 & 0.067 \\
\hline Commerce/logistics (wholesale, retail) & -4.241 & $0.022^{*}$ \\
\hline Service/general (restaurant, tourism, hotel, etc.) & -2.775 & 0.128 \\
\hline Finance/insurance/real estate & -3.686 & 0.083 \\
\hline Construction/Materials/Forestry & -2.764 & 0.178 \\
\hline Medical, welfare & -5.092 & $0.006^{* *}$ \\
\hline Other non-manufacturing industry & -2.672 & 0.121 \\
\hline Public-owned/public service (government/public enterprise/special corporation) & -3.357 & 0.132 \\
\hline (Less than 29) & & \\
\hline $30-99$ & -0.064 & 0.965 \\
\hline
\end{tabular}




\begin{tabular}{|c|c|c|}
\hline Continued & & \\
\hline $100-499$ & -0.457 & 0.749 \\
\hline 500 and more & -0.153 & 0.927 \\
\hline Number of people per office & -0.001 & 0.450 \\
\hline Number of people per department/section & 0.007 & 0.386 \\
\hline $\begin{array}{l}\text { Production (direct/indirect department of a factory, } \\
\text { etc. such as processing, assembly, inspection, and machine operation) }\end{array}$ & & \\
\hline Clerical & 2.292 & 0.285 \\
\hline Professional/technical (research and development, design, information processing, teacher, designer, etc.) & 2.834 & 0.159 \\
\hline Transportation (operation, maintenance, and loading/unloading of a transportation facility and related work) & 3.522 & 0.439 \\
\hline Business management/sales & -2.101 & 0.344 \\
\hline Other & 1.042 & 0.651 \\
\hline Labor union, yes & -1.853 & 0.062 \\
\hline Annual income (log) & -0.253 & 0.782 \\
\hline Actual working hours per week & -0.082 & 0.099 \\
\hline Predetermined non-work days per week & 2.113 & 0.148 \\
\hline Paid vacation days given & 0.458 & $0.000^{* * *}$ \\
\hline Share method & 3.846 & $0.027^{*}$ \\
\hline Progressive method & 4.601 & 0.056 \\
\hline (Regressive method) & & \\
\hline Self-pay method (advance) & 3.127 & 0.074 \\
\hline Self-pay method (arrears) & 3.070 & 0.113 \\
\hline Self-pay method (work at home) & 6.966 & $0.032^{*}$ \\
\hline Information sharing & -0.276 & 0.797 \\
\hline Sensitivity to other employees & -1.477 & 0.105 \\
\hline Work load management appropriate for personnel & 2.442 & $0.007^{* *}$ \\
\hline
\end{tabular}

Note 1: Estimated by the author. Note 2: Significant at the ${ }^{*} 5 \% ;{ }^{* *} 1 \% ;{ }^{* * *} 0.1 \%$ levels.

employees who utilized the "self-pay (advance)" method, which is the case in which replacement of work when taking paid vacation is difficult, was the highest; if enhancing interchangeability of work is successful, it is expected that workers will shift from the self-pay (advance) method to the share method, leading to a certain effect in increasing paid vacation usage.

The study also indicated that the number of days taken as paid vacation by those who used the self-pay (work at home) method was significantly high. In Japan, workers are evaluated not only for work capacity at a workplace, but for attitudes and behaviors in everyday life [7]. The fact that the cohesion of home and work when taking paid vacation significantly influences paid vacation usage goes against the intention of paid vacation (to release a worker from labor for a certain period of time with compensation) and the method should not be recommended even though it has a positive influence on the number. Under the recent labor management circumstances, workers "voluntarily" work even when there is no specific command through quota, etc. At least for paid vacation, it may be necessary for employers to prohibit employees to take their work home or to avoid giving tasks that cannot be processed within normal working hours. It is important to establish a workplace environment in which paid vacation is taken without working outside the workplace. As can be understood from research such as Wrinkler [6], absenteeism is an issue in the US and Europe but in Japan, the national character 
in which there is an issue of people even taking the paid vacation to which they are entitled is a barrier to the usage of paid vacation.

This paper focused on understanding the actual situation of the relationship between the paid vacation usage rate and the usage methods through questionnaires and quantitatively verifying the relationship using empirical analysis. However, since the rates of those who take paid vacation are different among the usage methods, it is necessary to maintain a constant sample size of each method by using stratified sampling, etc. in order to analyze the relationship more precisely. It is expected that a fundamental solution for the issue of unused paid vacation will be explored in future research.

\section{Conflict of Interest}

The author has no conflict of interest to declare.

\section{References}

[1] Ogura, K. (2003) Behaviors Concerning Paid Vacation Usage by Japanese-Economic Analysis of Paid Vacation. Japan Institute of Labour, Japan.

[2] Matsuzaki, Y. (1982) Analysis on Steel Industry in Japan. Nippon Hyoron Sha, Japan.

[3] Wakisaka, A. (2002) Conditions and Issues for Utilizing Childcare Leave System at a Workplace. Japan Institute of Labour Magazine, 44, 4-14.

[4] Igusa, G. (2011) Six Patterns of Paid Vacation Use: A Study Concerning the Management of Paid Vacation at a Workplace Level. Annual Review of Japanese Association of Labor Sociology, 22, 75-105.

[5] Hazama, H. (1989) Management Sociology. Yuhikaku Publishing, Japan.

[6] Wrinkler, D. (1980) The Effects of Sick-Leave Policy on Teacher Absenteeism. Industrial and Labor Relations Review, 33, 232-240. http://dx.doi.org/10.2307/2522452

[7] Yoshida, M. (2002) Nature of Work Hours Concerning Overtime Work at Home. Ritsumeikan Law Review, 286, 353-373. 


\section{Appendix}

\section{Survey Sheet}

\section{Survey on Paid Vacation Usage (2013)}

Please answer the following questions about yourself:

What is your highest educational achievement? (Please choose one).

1 Middle school

$4 \%$

$20 \%$

2 High school

$14 \%$

3 Vocational/other school

$8 \%$

4 Junior college/vocational high school

$44 \%$

5 Undergraduate school

$7 \%$

What is the main type of business of the company/office you work for? (Please choose one).

1 Manufacturing

$20 \%$

2 Resource/energy (electric power, gas, water)

3 Traffic/Transportation (railroad, road transport, transportation by water, aviation)

$4 \%$

$17 \%$

5 Commerce/logistics (wholesale, retail)

$11 \%$

6 Service/general (restaurants, tourism, hotels, etc.)

10 Other non-manufacturing industry

Which of the following options best describes the number of employees at your workplace (entire company)? (Please choose one).

129 or less

230 - 99

3100 - 499

$21 \%$

4500 and more

Please answer the number of employees/staff members per factory or office you work for.

( ) people Average 280.3

Please answer the number of employees/staff members in your department/section?

( ) people Average 39.0

Which of the following option best describes your work/job category at your workplace? (Please choose one).

1 Production (direct/indirect department of a factory, etc. such as processing, assembly, inspection, and machine operation)

2 Clerical

$20 \%$

3 Professional/technical (research and development, design, information processing, teacher, designer, etc.) 36\%

4 Transportation (operation, maintenance, and loading/unloading of a transportation facility and related work) 3\%

5 Business management/sales $\quad 20 \%$

$\begin{array}{ll}6 \text { Other } & 11 \%\end{array}$

Do you have a labor union at your workplace? (Please choose one).

1 Yes

2 No

What is your annual salary before taxes at your workplace last year? Please write an approximate amount below.
( ) 10 thousand yen
Average 481.3 10 thousand yen 
What are your actual working hours per week? Please answer your average hours.

About ( ) hours per week Average 7.7 hours

How many predetermined non-work days do you have per week?

( ) day(s) Average 1.9 days

How many new paid vacation days were you given for the previous year (FY2012)?

( ) days Average 16.4 days

How many paid vacation days did you take for the previous year (FY2012)?

( ) days Average 8.4 days

Which method do you mainly use when taking paid vacation? Please choose one that is closest to your situation.

1 Share method - The work of a person taking paid vacation is shared by his/her colleagues. 28\%

2 Progressive method-The work of a person taking paid vacation is passed down to an employee who handles tasks $\begin{array}{ll}\text { that are easier than that of the person taking paid vacation. } & 4 \%\end{array}$

3 Regressive method-The work of a person taking paid vacation is covered by his/her superior within the same group, team or section.

4 Self-pay method (advance)—When an employee plans to take paid vacation, s/he completes her/his tasks in advance.

5 Self-pay method (arrears)—An employee taking paid vacation completes the work of the paid vacation day later.

6 Self-pay method (work at home)_An employee taking paid vacation communicates closely with his/her workplace and handles tasks at home or at a travel destination.

Are you always making efforts to share information across the workplace? (Please choose one).

1 Yes

2 No

When trying to take paid vacation, do you have awareness such as "if I am not at the workplace, the work will be difficult," "the burden caused by my paid vacation will go to my colleagues," or "I will cause troubles for others”? (Please choose one).

1 Yes

2 No

At your workplace, is the work load management appropriate for personnel? (Please choose one).

1 Yes 
Scientific Research Publishing (SCIRP) is one of the largest Open Access journal publishers. It is currently publishing more than 200 open access, online, peer-reviewed journals covering a wide range of academic disciplines. SCIRP serves the worldwide academic communities and contributes to the progress and application of science with its publication.

Other selected journals from SCIRP are listed as below. Submit your manuscript to us via either submit@scirp.org or Online Submission Portal.
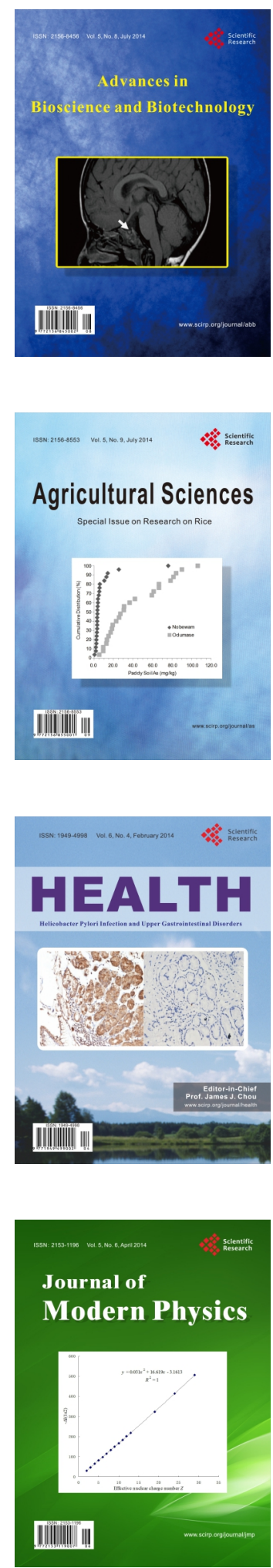
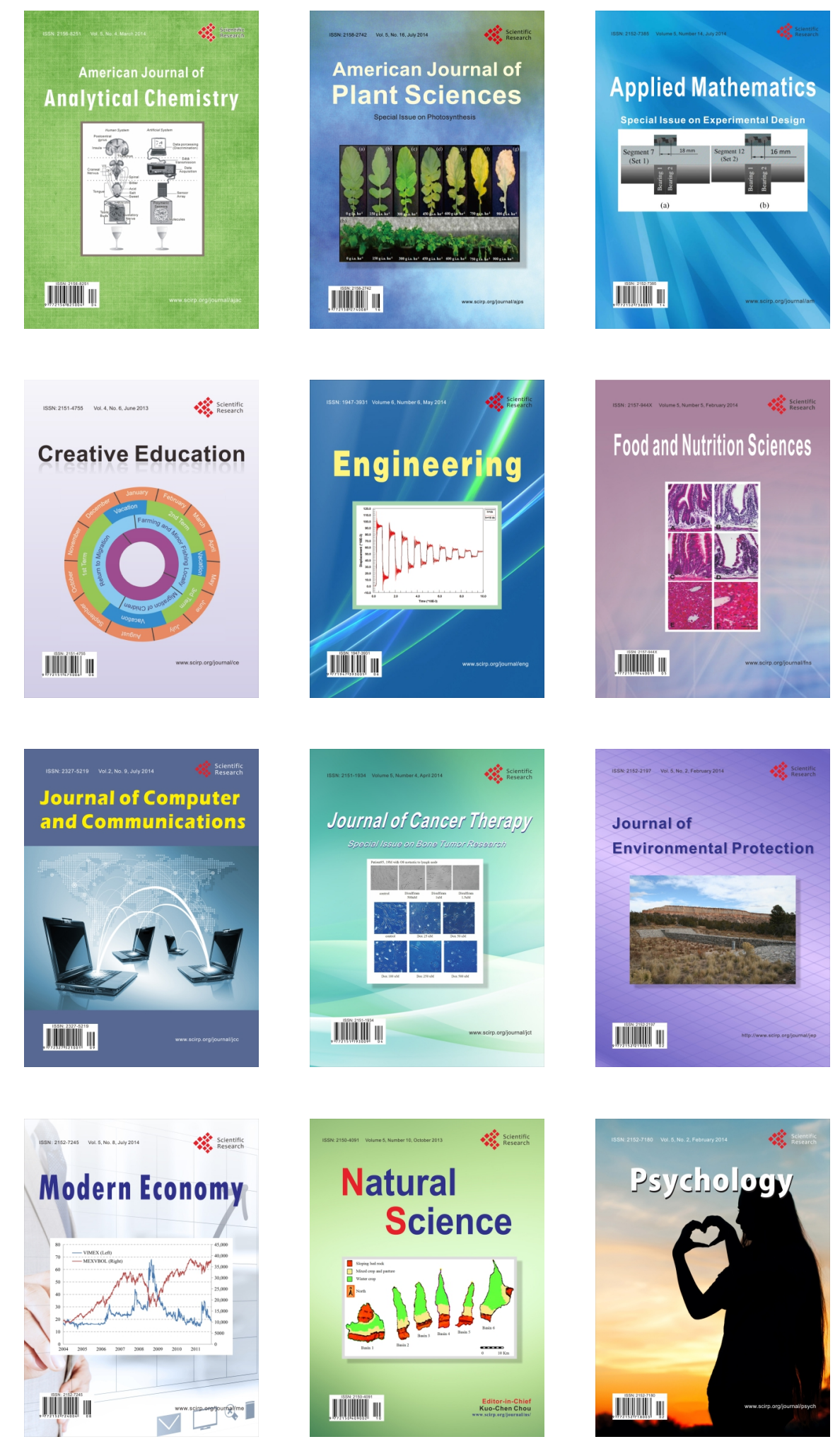